\title{
A review of tertiary BIM education for advanced engineering communication with visualization
}

\author{
Amarnath Chegu Badrinath, Yun-Tsui Chang and Shang-Hsien Hsieh ${ }^{*}$
}

\begin{abstract}
Background: Today, the architectural, engineering, construction, and operation (AECO) industry is motivated to employ graduates educated about Building Information Modeling (BIM) tools, techniques, and processes, which help them to better integrate visualizations and data into their projects. In line with today's AECO industry necessities and government mandates, globally active BIM educationalists and researchers are designing BIM educational frameworks, curricula and courses. These educationalists and researchers are also generating solutions to the obstacles faced during integration of BIM education into tertiary education systems (TESs). However, BIM researchers have taken few efforts recently to provide an overview of the level of BIM education across the globe through review and analysis of the latest publications associated with BIM education in TESs. Hence, this study attempts to fill this gap by providing a review of the efforts of globally active educationalists and researchers to educate AECO students about BIM in the context of advanced engineering education with visualization.
\end{abstract}

Method: In our study, an investigation of texts in the field of academic BIM education was conducted. Keywords such as "BIM education", "BIM curriculum", "BIM course", and "visualization in engineering education" were used to search for publications ranging from 2010 to the present day. Textual and content analysis were employed to arrange BIM-related qualitative textual data into similar sets of conceptual categories for the purpose of analyzing trends in today's global academic BIM education research.

Results: This study generated six conceptual categories by arranging qualitative textual data from 70 collected BIM publications in order to build an understanding of active BIM educationalists and researchers efforts: (a) identifying needs for BIM in tertiary educational institutions (TEIs), (b) identifying essential BIM skillsets for BIM education, (c) developing BIM educational frameworks, (d) developing BIM curricula, (e) experimenting with BIM courses, and (f) developing strategies to overcome BIM educational issues. Through this process of review and analysis, current research gaps in academic BIM education across the globe are identified.

Conclusion: This process of review and analysis of global BIM education research trends resulted in a conceptual categorization of BIM educationalists and researchers' efforts in TES. This categorization and review of the collected publications can serve as a knowledge base for: (a) identifying major issues involved in BIM education, (b) developing strategies to incorporate BIM into TES, and (c) developing BIM frameworks and curricula in the context of tertiary education, which can assist BIM educators with taking BIM education in TES to the next level for visualization in advanced engineering education. Through analyzing global BIM education research trends, this study also provides future research suggestions on academic BIM education across the globe. Furthermore, our analysis highlights the relationship between current tertiary BIM education and visualization.

Keywords: Visualization in engineering education, BIM educational framework, BIM curriculum, BIM course, BIM competencies, BIM educational issues

\footnotetext{
* Correspondence: shhsieh@ntu.edu.tw

Department of Civil, Engineering, National Taiwan University, No. 1, Sec. 4, Roosevelt Road, Taipei 10617, Taiwan
} 


\section{Introduction}

Traditional Computer-Aided Design (CAD) drawings (i.e., graphical entities such as dots, lines, and curves) and 3D models (i.e., 3D based presentations, rendering, walk-through, etc. to enhance model-based visualizations) have evolved into a new paradigm: intelligent Building Information Modeling (BIM). This tool consists of data-rich smart objects (defined in terms of building elements and systems such as spaces, walls, beams, and columns) being aggregated for the digital representation of physical and functional characteristics of facilities. Intelligent BIM has multiple dimensions from $3 \mathrm{D}$ to $n \mathrm{D}$-such as 3D-visualization, 4D-scheduling, 5Destimation, 6D-facility management applications, and 7D-sustainability-offering multiple benefits such as BIM model use throughout the building life cycle (Computer Integrated Construction Research Group 2011; Succar 2015). Hence, intelligent BIM provides an opportunity for Architectural, Engineering, Construction, and Operation (AECO) industry stakeholders to evaluate possible solutions and identify potential problems of the final product before the start of actual construction. The most common use of intelligent BIM is visualization, and the most essential part of visualization in engineering is communication. Visualization can enhance the communication between AECO industry stakeholders, and result in better understanding of what a client is asking for. Advanced visualization techniques also improve the efficiency of information exchange in the context of AECO education in tertiary education systems (TESs), assisting AECO students in solving geometric tasks. Hence, the use of CAD and intelligent BIM, technological advances in spatial representation, and conceptual skills by which users can make intuitive decisions about spatial problems are all essential to delivering better education for AECO students. Moreover, introducing AECO students to modern BIM technology, tools, and related processes will allow them to be further competitive and flexible in a rapidly changing Information Technology (IT) environment (Hsieh et al. 2015).

Based on today's AECO industry expectations and government mandates, many educational institutions across the globe are investigating how to incorporate BIM in TESs (Becker et al. 2011; Salman 2014; Rooney 2015). In addition, globally active BIM educationalists and researchers have invested huge efforts in delivering BIM educational frameworks, designing BIM curricula, conducting BIM courses, and developing new strategies for overcoming the obstacles faced during BIM implementation. Relatedly, a few BIM educationalists and researchers have delivered overviews of BIM educational trends in the past (Barison \& Santos 2010c, 2011; Wong et al. 2011; Lee \& Dossick 2012). Recently, NATSPEC, a non-profit organization published an update on the state of BIM awareness and adoption in countries such as the USA, Canada, the Czech Republic, Finland, the Netherlands, Norway, the UK, South Africa, China, Hong Kong, Singapore, Japan, Australia, and New Zealand. NATSPEC's study revealed that BIM education and its uptake are still at different levels of implementation across the globe, and provided an outline declaring that current BIM education tends to focus on the use of particular BIM software. In the end, NATSPEC's report emphasized the need for education connected to open BIM, BIM management, and a collaborative working environment for them (Rooney 2015). Open BIM and BIM management in academic BIM education refers to educating AECO students on how students of different disciplines need to collaboratively design, construct, and operate buildings based on open standards and workflows. However, NATSPEC's study failed to document completely the status of BIM education and awareness in each country. Another drawback was that the report was purely based on the responses provided by a global group of parties with an interest in BIM. Moreover, no recent efforts have been undertaken by BIM researchers to review and analyze the latest BIM publications in order to provide an overview of the state of BIM education worldwide.

In line with today's necessities, this study reviewed and analyzed 70 BIM education-related publications ranging from 2010 to the present day from 24 countries by combining textual and content analysis. This process of literature review of global BIM education research trends resulted in six conceptual categories of BIM educationalists and researchers' efforts in TESs as described in Fig. 1: (a) identifying needs for BIM in tertiary educational institutions (TEIs), (b) identifying essential BIM skillsets for BIM education, (c) developing BIM educational frameworks, (d) developing BIM curricula, (e) experimenting with BIM courses, and (f) developing strategies to overcome BIM educational issues. An interactive map, in which detailed information behind this conceptual categorization and associated BIM education publications are visualized, is accessible through the following link: https://public.tableau.com/views/AcademicBIMEducation/Dashboard1?:embed=y\&:display_cou nt=yea\&:showTabs=y. These categories show that these global BIM educationalists and researchers have been addressing the questions of (a) "why" we need BIM education for TEIs, (b) "what" to teach in academic BIM education, and (c) "how" to develop academic BIM education at different working levels (i.e. the framework, curriculum, and course levels) and overcome related barriers, in order to take BIM education in TESs to next level. These categories are arranged according to the flow of BIM education development flow to help BIM educators to 


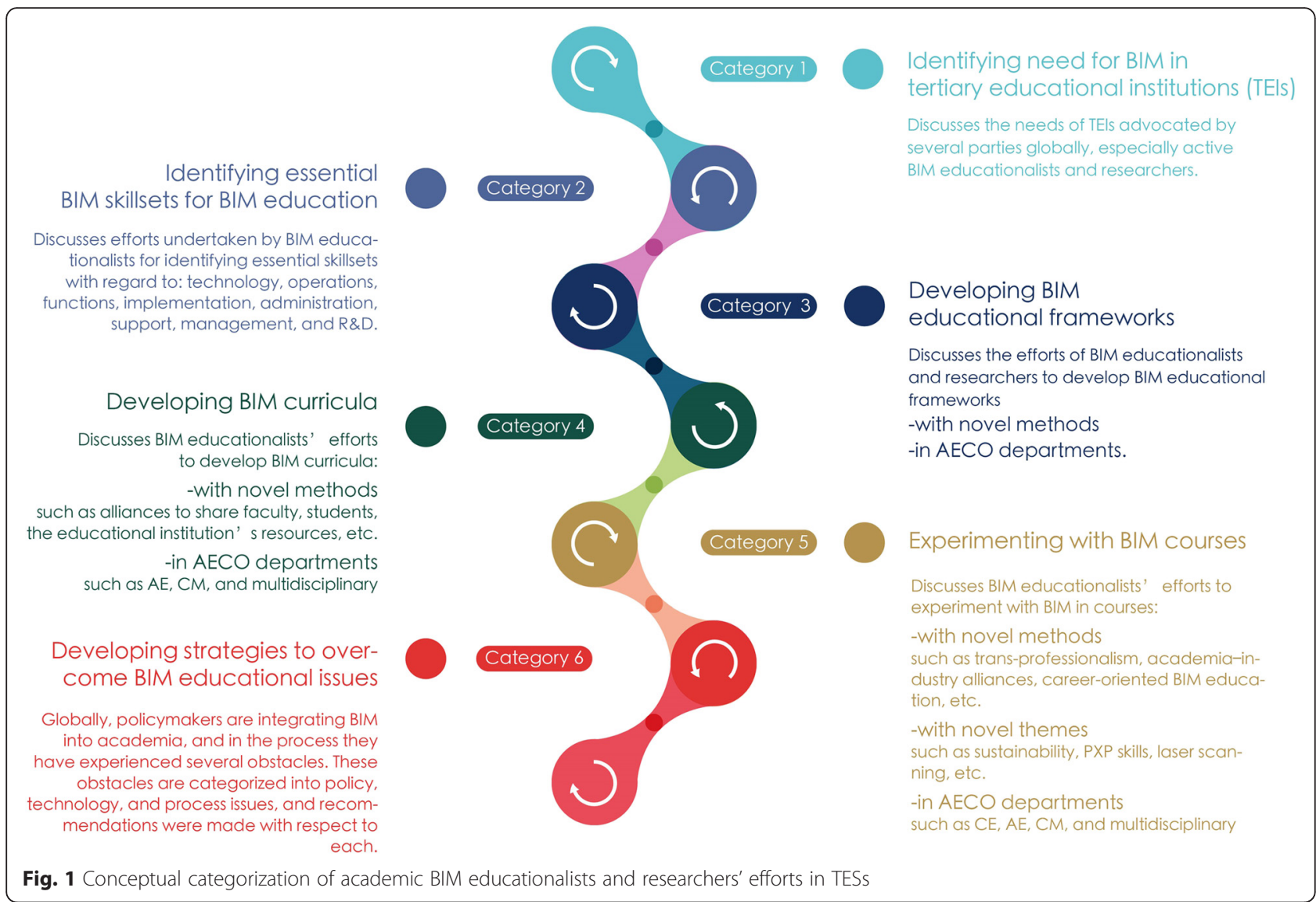

understand issues they ought to consider in different phases of BIM education development. This categorization and review of the publications collected in this study can serve as a knowledge base for: (a) realizing major issues involved in BIM education, (b) developing strategies for incorporating BIM into TES, and (c) developing BIM tertiary education frameworks and curricula that can assist BIM educators in taking BIM education in TESs to the next level in the context of advanced engineering education with visualizations. Through analyzing global BIM education research trends, this study also provides future research suggestions on academic BIM education across the globe. Furthermore, our analysis highlights the relationship between current tertiary BIM education and visualization. This study mainly concentrates on delivering an overview of BIM teaching at universities: i.e., on academic BIM education and not on BIM training in the AECO industry.

\section{Overview of latest academic BIM education publications}

In our study, an investigation of the latest publications on academic BIM education has been conducted. Keywords such as "academic BIM education", "BIM curriculum", and "BIM course" were used to select publications ranging from 2010 to the present day using different search engines (e.g., Google Scholar, Scopus), resulting in the collection of 70 academic BIM education publications. The composition of these publications is shown in Fig. 2. Almost half of the publications are published in 2015 (30 out of 70), showing that the importance of BIM education at TESs has recently been recognized by educationalists and researchers in AECO disciplines across the globe. Among these 70 publications, the majority of them are conference papers (50 out of 70 , accounting for $71 \%$ ). Only 17 of them are journal papers, while 2 are reports and 1 is a book chapter. The composition of publication types across the literature shows that there are plenty of sharing of case studies of and experiences with BIM education in academia through international conferences, yet there is a shortage of publications in international journals constituting deeper research into academic BIM education.

These academic BIM education publications were authored by researchers from 24 countries (the USA, Brazil, Mexico, the UK, Ireland, Finland, Denmark, Belgium, the Netherlands, Austria, Portugal, Latvia, Turkey, Egypt, the UAE, Israel, Nigeria, Indonesia, Singapore, Malaysia, India, Hong Kong, Taiwan, South Korea, and Australia). The global distribution of these 


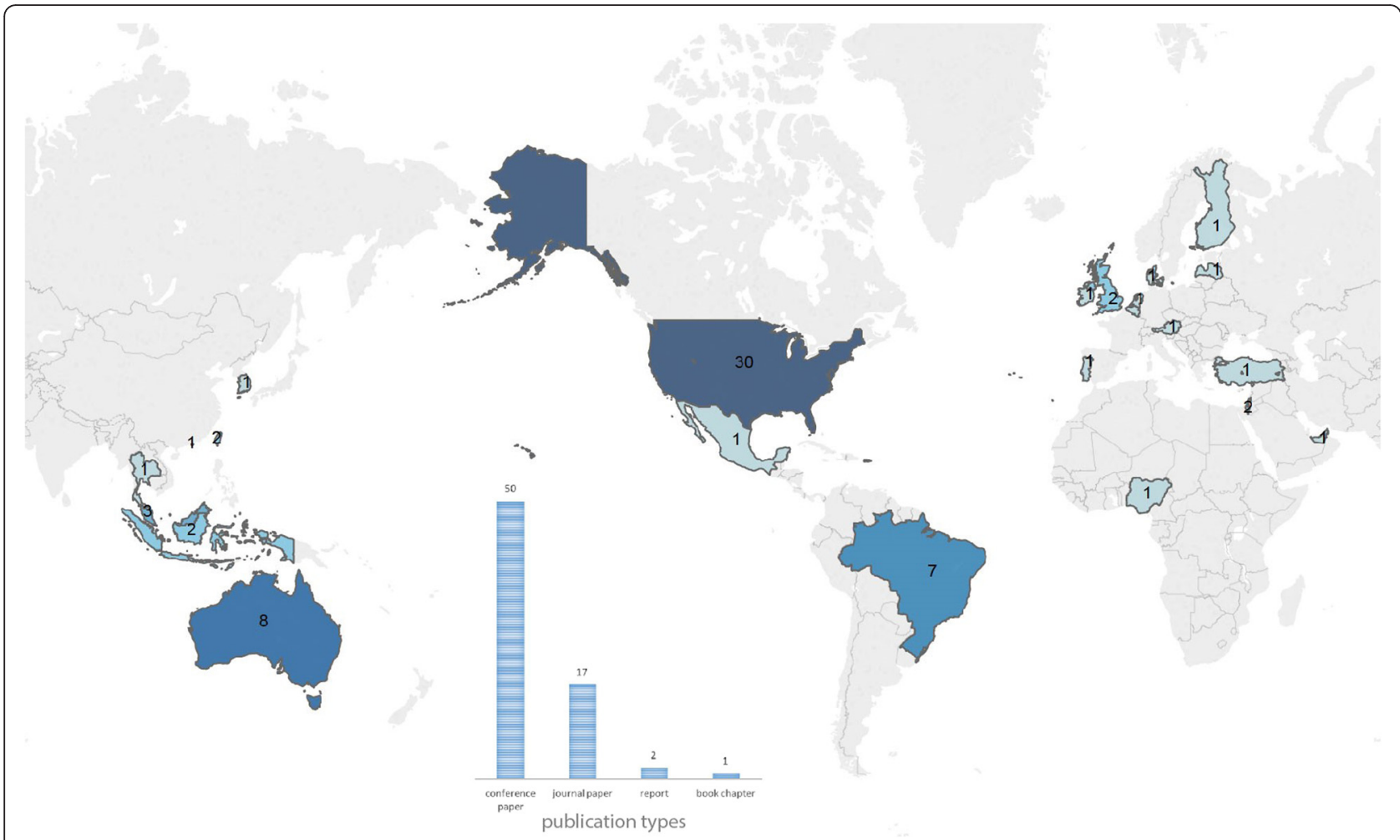

Fig. 2 Number of academic BIM education publications by publication type and author location

70 publications is shown in Fig. 2. Researchers in USA, Australia, and Brazil have published more BIM education-related publications than other countries in the period evaluated $(30,8$, and 7 publications, respectively). Their intensive discussion and development of academic BIM education provided rich experiences and knowledge from which educationalists and researchers in other regions and countries could learn. As for Europe, there were only 2 publications authored by UK academics, despite the strong need for academic BIM education in the UK due to the 2016 BIM mandate plan released by the government, and despite the existence of a national organization promoting academic BIM education there (i.e., the BIM Academic Forum by UK BIM Task Group) (Underwood \& Ayoade 2015). UK BIM education researchers could share more of their experiences with and knowledge about academic BIM education in the future. Beside the UK, there were only 8 publications concerning academic BIM education authored by researchers in 8 European countries (i.e., Ireland, Finland, Denmark, Belgium, the Netherlands, Austria, Portugal, and Latvia). Language barriers need to be overcome for educationalists and researchers in this region to share more of their efforts to the global tertiary BIM education community. Compared with the European region, researchers from 7 Asian countries have published 9 publications in which they share their experiences with academic BIM education. This shows that Asian countries are not only keen to promote BIM at the moment (Cheng \& Lu 2015), but also that researchers in this area are keen to promote academic BIM education and exchange their experiences.

\section{Identifying needs for BIM in tertiary educational institutions}

Tertiary education, also referred as third-stage, thirdlevel, and post-secondary education, is the educational level following the completion of a secondary education institution. At this higher education level within AECO departments, integrating BIM in their curricula is the most essential step for them to cope with today's AECO industry requirements. TEIs must deliver BIM education with different course levels in curricula by adopting BIM in AECO departments within major core courses and expanding the curricula to create a BIM learning spectrum with various modes of collaboration. With respect to the above requirements, it is also recommended to set-up multidisciplinary schools and BIM educational institutions to facilitate BIM learning through industry and academia (AIA-CA 2012; McDonald \& Donohoe 2013). Several of the publications we collected identified the need for BIM in TESs (Agboola \& Elinwa 2013; Sampaio 2014; Rooney 2015). 
For instance, Agboola and Elinwa (2013) suggested the need for a global accreditation model to enhance uniformity in TESs. Agboola and Elinwa's study provided an overview of the Nigerian National Universities Commission's accreditation of engineering education, and made recommendations to policy-makers in government and the educational sector about how to redesign, upgrade, and modify existing initiatives to produce graduates who can compete favorably in the engineering sector worldwide. Sampaio (2014) identified the role of engineering schools in promoting BIM concepts, and described several educational measures on offer at the Technical University of Lisbon, Portugal. She highlighted the importance of teaching BIM in TEIs, the involvement of students in research projects, and the dissemination of BIM through short courses and workshops addressed to the AEC community outside the school. Recently, the NATSPEC's global summary report, based purely on responses received from a global group of parties with interest in BIM, advocated the need for TEIs with backing from industry and government to fully incorporate BIM education into curricula (Rooney 2015). This report attempted to fully document the status of BIM education/awareness by considering three key factors-education/training, initiatives/organizations, and awareness/uptake-in countries such as Canada, US, UK, the Netherlands, the Czech Republic, Finland, Norway, South Africa, China, Hong Kong, Singapore, Japan, Australia, and New Zealand. NATSPEC's report revealed that BIM awareness and uptake appear to still be on the rise, with BIM widely adopted by practitioners in the AECO industry, and with the governments of a few countries such as UK and Singapore actively promoting and mandating the use of BIM. Together, these studies recommend the need for a global accreditation model, multidisciplinary schools, and BIM educational institutions with industry and government backing to facilitate BIM learning throughout industry and academia.

Even though the NATSPEC report has highlighted the present need for BIM education at TESs worldwide, only a few publications in recent years have discussed and analyzed the specific needs of the AECO industry with regard to academic BIM education in the contexts of different countries (e.g., McDonald \& Donohoe 2013; Agboola \& Elinwa 2013). Discussion on academic BIM education in the contexts of different countries is a potential research direction for BIM education researchers to follow in order to meet the industry need of cultivating BIM-ready graduates in different places around the world.

\section{Identifying essential BIM skillsets for BIM education}

Different AECO industry specialists need distinct BIM knowledge and skillsets. AECO students, who will be future BIM specialists, need to be trained to acquire such essential competencies. Planning this training must consider various aspects: technical aspects (including modelling, drafting, and model management), operational considerations (including designing, simulating, and quantifying), functional concerns (including collaboration, facilitation, and project management), implementation (including component development, standardization, and technical training), administrative procedures (including tendering and procurement, contract management, and human resource management), support (including data and network support, equipment, and software troubleshooting), managerial concepts (including leadership, strategic planning, and organizational management) and $R \& D$ (including change management, knowledge engineering, and industry engagement) (Succar \& Sher, 2014). Here, the term BIM specialist refers to any of BIM modelers, BIM analysts, BIM application/software developers, BIM managers/coordinators, BIM consultants, and BIM researchers. BIM educationalists train these future specialists with the unique BIM skillsets required by adopting certain training techniques.

Active BIM educationalists in Brazil and Australia have put efforts in identifying essential BIM skillsets for BIM education in their TEIs. Barison and Santos (2010b, 2011, 2012a) conducted an extensive literature survey to guide the drafting of BIM skillset requirements of AECO industry specialists. In 2010, they provided a preliminary outline of BIM specialists and their responsibilities. In 2011, this team emphasized the need for educational institutions to focus education on cultivating in their students the educational competencies required for them to become BIM managers and specialists. Through their technical literature review, they revealed that a BIM manager must be adept at working with computers and have detailed planning skills in order to create a good visualization of the building before its construction. Considering BIM implementation in Brazil context in 2012, they provided a brief report on BIM skills that need to be considered in academic institutions at the graduate level. Recently, Gardner et al. (2014) from southern Australia highlighted essential BIM skills such as collaboration, communication, leadership, and facilitating change management alongside technical skills through interviews with local BIM specialists.

Even though these researchers have attempted to identify the essential BIM skillsets to be taught in TEIs, only BIM skillsets for a few AECO disciplines and BIM specialists have been addressed. For instance, in Barison and Santos' works, only the competencies of BIM managers (Barison and Santos 2010a) and the BIM competencies for the field of architectural and civil engineering (Barison and Santos 2012a) have been addressed with respect to BIM education. More research needs to be 
done to fill this gap in order to know how to educate competent BIM graduates in TEIs in the future.

\section{Developing BIM educational framework}

A BIM educational framework is an organized set of criteria or learning outcomes that defines the BIM content for AECO students to learn throughout their tertiary education levels in order to be transformed into BIM-ready graduates. In recent years, there have been several studies about delivering educational frameworks that can enhance BIM education within TESs. To deliver an overview of BIM educationalists' efforts to deliver these frameworks, we have identified the specific development methods and AECO applications they have focused on. The section below describes these subcategories in detail.

\section{With novel methods}

BIM educationalists in Australia and Brazil have been working on methods to develop BIM educational frameworks. MacDonald (2012) from University of Technology Sydney, Australia has developed an "IMAC framework" with four stages: illustration, manipulation, application, and collaboration. These stages relate to different levels of achievement and each consists of two components: a benchmarking tool and a guide for implementation, thereby assisting educators in benchmarking their curriculum and in developing their own strategies. Here, we further describe in detail the activities within the IMAC framework in each stage. (a) In the illustration stage, building information models are used to illustrate key concepts in students' respective disciplines. (b) In the manipulation stage, students interact with and manipulate existing models. (c) In the application stage, students solve discipline-related problems arising from the basic theoretical knowledge they have acquired thus far. (d) In the collaboration stage, students from different disciplines work together on joint projects.

Following a series of work on academic BIM education in Brazil, Barison and Santos (2013) have reviewed and analyzed 306 documents using the content analysis method to establish educational activities. They address several variables that may influence the choice of educational activities in order to plan educational activities for the teaching and learning of BIM in the context of model authoring. These variables include the learning objectives and requisites, the structures of the subjects to be taught, the phase in the teaching process, the teacher's teaching experience, the available teaching time and resources, and the type of required learning.

\section{In AECO departments}

AECO departments refer to those departments in TESs connected with the AECO industry: e.g., architectural engineering ( $\mathrm{AE})$, civil engineering (CE), construction engineering and management (CEM), quantity surveying (QS), building and real estate (BRE), etc. Active BIM educationalists and researchers in USA and Israel have developed BIM educational frameworks to apply in CE and QS departments, which are further discussed in detail below.

- Construction Engineering and Management Active educationalists (Sacks \& Pikas 2013, Pikas et al. 2013) from the Civil and Environmental Engineering Department at the Technion-Israel Institute of Technology, Israel conducted a series of studies to compile a framework for BIM education that lays out necessary topics and levels of achievement required at each stage of a degree program for CEM. They also contributed towards creating a set of procedures that educators can use for identifying their local requirements and for building comprehensive BIM education into their CEM curriculum. They highlighted the requirement of high-level competence in performing 4D visualization of construction schedules in BIM education for CEM.

- Quantity Surveying Ali et al. (2015) from Universiti Teknologi Malaysia developed an educational framework for QS that charts a route on how knowledge related to BIM principles and its applications can be imparted to interdisciplinary design and construction with a primary focus on the QS scope of work. Through an analysis of past BIM education frameworks, they divided the QS BIM framework into four objectives: visualization, quantification, planning/scheduling, and management. These developed frameworks can assist educators with integrating BIM into their respective departmental courses.

- Multidisciplinary

As mentioned in the first conceptual category above (i.e. identifying needs for BIM in TEIs), setting up multidisciplinary schools and BIM institutions is recommended in order to facilitate BIM learning through industry and academia (AIA-CA 2012; McDonald \& Donohoe 2013). BIM educationalists and researchers in South Korea, Australia, Brazil, and Singapore have contributed to developing BIM educational frameworks for multidisciplinary BIM education to produce BIM-ready graduates. In 2011, South Korean BIM activists developed eduBIM, the first private BIM "U-education system" (i.e. customized self-learning system) with an open BIM library. The system specifically uses a BIM education process based on worker competencies, present structure of the overall system and services, educational experiences, and recommendations. The unique feature of this BIM U-education system is its 
capability of supporting learners' acquisition of BIM processes by work type (Jeon \& Eom 2011). Most recently, BIM educationalists in Singapore designed a truly qualified BIM educational program to develop and implement an internationally recognized, standalone, post-graduate education program and subsequent certification for qualified BIM practitioners. This research was created as a foundation for the education model of the Institute of Virtual Design and Construction, a private educational institution registered in Vietnam and Singapore. It also describes in detail three essential levels of a BIM curriculum: L1: BIM modelling by providing introduction, modelling and procedures, and data management; L2: BIM coordination by educating students about collaboration, calculation, estimation and scheduling, sustainability and coordination; and L3: BIM management by educating students about advanced modeling, technologies, management, and training (Hoang \& Bedrick 2015).

A well-defined educational framework is important for the delivery of BIM education. However, compared with the considerable amount of publications discussing curriculum development and experimenting with courses for BIM education we found, only a few publications discuss the development of educational frameworks for academic BIM education. Moreover, only a few AECO departments have attempted to design educational frameworks specific for BIM. More research should be done in the future corresponding to these research gaps. Moreover, few publications discussed the relationships and differences between BIM education in different levels of TESs (e.g. undergraduate, graduate, and postgraduate institutions). This is another research direction for BIM researchers to consider in order to design a BIM education framework that meets the needs of different educational levels.

\section{Developing BIM curricula}

BIM-related curriculum development is a process of improving the current curricula of AECO departments. The process of introducing BIM into AECO departments has revealed that this process is more complex than just adding new courses into the curriculum. A generally adopted process for curriculum development includes five steps: (1) analysis, (2) objective design, (3) selection of appropriate teaching, learning, and assessment methods, (4) formation of curriculum implementation and evaluation committee, and (5) curriculum review. BIM has the potential to be an intrinsic part of AECO industry disciplines: thus, many criteria need to be considered while planning and developing BIM curricula. These criteria include prerequisites, goals, objectives, contents, teaching methodologies, and evaluations.

A large and growing body of literature has investigated BIM curriculum design. To start with, Barison and Santos (2010a, 2010b) conducted an extensive literature survey to analyze current strategies of planning a BIM curriculum, describing how a few BIM courses have been planned, introduced, developed, and evaluated. Barison and Santos also discussed issues that arise while promoting BIM education and suggested different approaches to incorporate BIM into curricula. Further, Becker et al. (2011) reviewed research that used scientific methodologies to make predictions about trends in BIM education. They also made specific recommendations for constructing curricula that could provide students with expected proficiencies.

Besides these literature review papers on BIM curriculum design, there have been several studies surveying how BIM is incorporated into AECO programs and curricula. Becerik-Gerber et al. (2011) surveyed how the educational innovations of distance learning, multidisciplinary collaboration, and industry collaborations have been incorporated into 101 U.S. AEC programs in the subject area of BIM. They also surveyed the challenges faced while incorporating BIM into constrained curricula and the various approaches that have been undertaken to address them. Their study showed that currently, BIM is mostly used in teaching design visualization and constructability activities among these AEC programs, and these two aspects are also the areas in which programs would like to further expand the use of BIM. Joannides et al. (2012) evaluated the current implementation of BIM and identified trends in the teaching of BIM in 81 architecture and construction academic programs in the USA. Their results showed that more architecture schools have implemented BIM into their curriculum than construction schools, and that many more construction schools focus on 4D and 5D models in teaching scheduling and estimating compared with architecture schools.

In the next section, to present a detailed overview on BIM educationalists' efforts towards BIM curriculum development, we have identified their focuses on specific development methods and on specific AECO applications. The section below describes these subcategories in detail.

\section{With novel methods}

In TESs, curriculum development involves the use of several methods, tools, and techniques. Several BIM educationalists and researchers have been focusing on the development of such methods, tools, and techniques for their BIM curricula. 
A team of educationalists from Australia worked on BIM competency identification to facilitate the development of BIM learning modules. This team also developed an integrated approach to BIM competency assessment, acquisition, and application (Succar \& Sher 2013; Succar et al. 2013). Brazilian educationalists and researchers produced curriculum development tools utilizing best practices that can assist teachers in planning basic BIM and collaborative design courses (Barison \& Santos 2014). Also, a few BIM educationalists from the USA developed BIM curricula by employing several techniques such as flip classroom techniques, and later discussed their pros and cons (Dossick et al. 2015).

\section{In AECO departments}

In AECO departments, BIM educationalists and researchers in $\mathrm{AE}$ and CEM departments are actively designing BIM-based curricula. A few initiatives were also undertaken in designing multidisciplinary team-based BIM curricula for training AECO students to gain collaboration, communication and coordination skillsets.

- Architectural Engineering

Architectural engineering, also known as building engineering, is the application of engineering principles and technology to design and construction. Students in such a department should possess a global perspective on how to address the visual, technical, functional, and aesthetic aspects of inhabited spaces within the parameters of ecological contexts.

BIM educationalists from Turkey and USA made progress in developing effective approaches to design BIM education in the context of an architecture program (Elinwa \& Agboola 2013; Cribbs et al. 2015). Elinwa and Agboola (2013) from Eastern Mediterranean University, Turkey considered an effective approach to educational design in architecture schools through the enhancement of their architectural program's curriculum with BIM pedagogy so that the program can meet current architectural challenges.

- Construction Engineering and Management Construction engineering and management (CEM) is the overall planning, coordination, and control of a project from beginning to completion, aimed at meeting the client's requirements in order to produce a functionally and financially viable project. Globally, CEM programs are actively seeking to integrate BIM into their curricula.

For instance, Lee and Dossick (2012) analyzed various applications of BIM in CEM programs from the literature, and established a BIM educational program in their curriculum for educating students that would be well prepared for the construction industry. The study indicated that the CEM curriculum was designed by educationalists with courses in numerous categories, such as stand-alone BIM courses, MEP lab courses, engineering graphics courses, cross-curriculum teaching modules, capstone courses, scheduling and estimating courses, and project management courses. The study also suggested introducing general types of BIM technology to support the CEM curriculum with 3D visualization, 4D scheduling, 5D estimation, and laser scanning technology, and described further on how to integrate BIM into other CEM courses such as construction contracts, construction surveying, facility management (FM), construction safety, construction estimating, construction planning and scheduling, project administration, capstone courses, and integrated studios. In the same series of studies, Lee et al. (2013) further conducted research with a main objective of identifying the best approach to incorporate BIM into the CM curricula at East Carolina University and University of Washington. Here, Lee et al.'s study mainly reported on some published cases, learning outcomes, challenges of BIM in construction education, and associated industry perspectives. They also developed detailed guidelines for integrating BIM technical and management skills into construction education. Likewise, BIM educationalists Liu and Hatipkarasulu (2014) from The University of Texas at San Antonio, USA designed a course titled "BIM for CM". Its combined lecture-lab structure provided an example of BIM content being delivered in a newly developed construction program for students, thereby serving different needs of students at different levels of computer skills and with different industry experiences. In addition, Liu and Hatipkarasulu discussed subjects covered within this standalone course, its grading structure, content delivery methods, term projects, student feedback, and lessons learned. Recently, Salazar et al. (2015) described the approach taken in developing a BIMbased platform and virtual prototype to efficiently incorporate virtual construction in CE courses. In this study, his team built a BIM-based platform to support delivery of construction methods and virtual construction courses at two different universities-Worcester Polytechnic Institute, USA and Universidad Autonoma de Yucatan, Mexico-in both undergraduate and graduate courses. Their study results indicated that their approach satisfies their educational needs within the constraints imposed by time and continuous technological change. 
- Multidisciplinary

A multidisciplinary approach to BIM education involves gathering students from multiple disciplines to redefine problems outside normal boundaries and reaching solutions based on understanding of real AECO-industry projects, processes, and current issues. It is vital to see that educators at the university level adapt BIM curricula for their students so that they not only understand the basic concepts and proper usages of BIM, but also learn in an environment where collaboration is not merely encouraged but engrained in the culture.

Canada, the USA, and Hong Kong's BIM educationalists and researchers invested their efforts in designing curricula for multidisciplinary design studios. These multidisciplinary design studios involve AECO students in the disciplines of CM, building technology, MEP, and QS (Wong et al. 2011; Demirdoven 2015; Henderson \& Jordan 2015). Wong et al. (2011) at PolyU in Hong Kong incorporated BIM into their CM, building technology, and QS curricula while focusing on the institutional policy. Moreover, BIM courses at B\&RE in PolyU was introduced at different education levels such as the diploma, undergraduate and graduate levels. Likewise, Demirdoven (2015) from the USA, who belongs to a department of architectural, civil and environmental engineering, visualized the benefits of BIM-based interdisciplinary coursework for training senior and graduate level students at the Illinois institute of Technology, Chicago.

Recently, Henderson and Jordan (2015) took the unique approach of proposing a trans-disciplinary "building life-cycle" graduate curriculum, attempting to design an academic program that resolves many of the conflicts and problems in educating professionals within the building industry: i.e. owners, designers, contractors, facility managers and users. The core of this trans-disciplinary building life-cycle program was divided into four major syllabus components: demand, acquisition of facilities, facilities in use, and demolition/reuse. This trans-disciplinary curriculum is markedly different from other multi-disciplinary BIM curriculums developed to-date. In addition, BIM educationalists Cribbs et al. (2015) developed a BIM curriculum for enhancing the educational value of an existing graduate-level BIM course at Arizona State University (ASU). Here, the curriculum designed ultimately provided students with experience through an applied project that would benefit them directly in the industry. BIM education and curriculum development has evolved at ASU's Design School from 2008 to date with many enhancements. In 2008, they performed a survey to gauge industry requirements; in 2009, they introduced education about theoretical BIM; in 2010, they disconnected BIM from other modules; in 2011 they made improvements; in 2012, they included collaboration of students from AECO disciplines; and in 2014, they vertically integrated all the courses. They stated that, in essence, the use of BIM facilitates a complete visualization of resultant physical systems and management implications on design decisions. Hence, integration of BIM into the process allows students to simulate the "complex whole" of a proposed building. The approach for BIM education deployed by authors is regarded as a stepping stone towards an integrative designbuilding program at ASU in which a model-based deliverable becomes commonplace.

As we have reviewed, there are many BIM educationalists and researchers working on BIM curriculum development, adopting several methods in several AECO departments, especially construction engineering and management departments. However, corresponding efforts towards several core AECO departments (e.g. architectural and civil engineering) are missing. BIM researchers and educationalists across the globe should address this gap in the near future.

\section{Experimenting with BIM courses}

Globally, educationalists and researchers are experimenting with BIM and integrating it within AECO departmental core courses with novel methods (open resources, professor-student collaboration, project-based learning, team processes, industry-academia alliances, career-oriented BIM education, etc.) and with novel themes (sustainability with green concepts, project execution-planning processes, etc.) for assessing key benefits of BIM in order to advance their curricula. In recent years, there has been an increasing amount of literature on planning, designing, testing and evaluating BIM courses. To deliver an overview of BIM educationalists' efforts in experimenting with BIM in AECO department courses, we have identified their focuses on specific methods, concepts adopted, and disciplinespecific AECO applications. The section below describes these subcategories in detail.

\section{With novel methods}

In TES, teaching methods consist of several tools and techniques, which are used by academics to achieve a desired level of learning in students. Moreover, to make a particular teaching method appropriate and efficient, the characteristics of learners and the type of learning should be taken into consideration. Several BIM 
educationalists have been experimenting with BIM in AECO department courses while adopting several methods.

A few BIM educationalists from the UAE experimented with BIM courses by employing several techniques such as adopting alliance types and sharing faculty, students, and educational institution resources (Heintz 2010). Dederichs et al. (2010) from Denmark investigated changes in collaboration over time as well as the function of trans-professionalism by characterizing the collaboration of professor and students during a course at the CE Department of Technical University, Denmark. Trans-professional practices are defined here as methods where specialists have deep insights in other specializations relevant for the overall process. Adopting these techniques will help to reduce the segregation of roles played by different professionals in the traditional construction process and reduce the hindrance caused by the rapid growth in professional practice. During this course, students were active, worked independently, and appreciated trans-professionalism. In addition, teamwork among students and professors resulted in uniform team structure and decision making by consensus, which in turn resulted in overall good solutions.

Wu and Issa (2013) expected to facilitate rethinking and enhance collaboration between educational and professional communities to promote career-oriented BIM education. A comparative BIM survey was conducted to identify discrepancies between existing BIM curriculum development and industry expectations, which finally resulted in rethinking and enhancing collaboration between industry and academia. Meanwhile, Suwal et al. (2014) from the School of Civil Engineering and Building Services (SCEBS) of Metropolia University of Applied Sciences, Finland highlighted the present lack of skilled BIM educators, calling for the education of BIM educators. Their study described both the initiation and results derived from an "OpeBIM" (BIM for teachers) program implemented to educate teachers in BIM education.

In recent months, Wu and Luo (2015) from California State University, USA provided a timely example of developing effective measures using a "project based learning" (PBL) technique to enhance student learning outcomes for BIM implementation in the domain of sustainability. PBL is recognized as an effective studentcentered pedagogical approach focusing on real-world issues, which allows students to build knowledge and to develop critical thinking, creativity, leadership, and communication. In this study, PBL was able to uncover issues that are atypical in conventional lectures. Graham et al. (2015) from North Carolina A\&T State University, USA discussed experimentation with a dedicated standalone BIM course and BIM-integrated senior capstone course in alliance with an industry partner. They also outlined the alliance formation process as well as issues and challenges faced. Modified techniques such as "collaborative team teaching" were embraced in this course: e.g., teaching BIM in a senior capstone course with assigned industry BIM experts; the official class instructor being a senior faculty member with expertise in BIM, Architecture, and CM; and other faculty members being tasked with specific responsibilities in order to achieve the goals of the alliance. Another team of architecture department educationalists, Gegana and Widjarnarso (2015) from Indonesia, presented two samples on how a BIM course has been integrated in curricula of TEIs in Indonesia. Their results showcased how BIM can be integrated in school curricula by adopting several techniques and methods to expand BIM courses inwards or outwards, to existing or new courses, to inner exploration or multidiscipline collaboration.

These cases clearly represent that BIM educationalists are recently exhibiting special attention towards designing courses with several techniques and strategies for delivering BIM education to AECO students.

\section{With novel themes}

BIM educationalists in the USA have taught several novel themes for AECO education by applying BIM. These educationalists experimented with BIM courses by integrating novel themes such as sustainability with green concepts, project execution-planning processes, and laser-scanning technology for rehabilitation as the main focuses of their AECO department courses.

Recently, Stone and King (2015) discussed the detailed design of a course that requires AECO students to look at the issues surrounding sustainable design through an investigation into "design for disassembly": i.e., designing building components for reuse, re-manufacture, or recycle. This course illustrated the usage of BIM as a design and research tool to help undergraduate students studying for a fine arts degree in interior architecture at Woodbury University to accomplish their learning goals. The course can be understood in terms of three categories. (1) Sustainability and life cycle analysis: to grasp concepts, principles, and theories of sustainability as they pertain to building methods, materials, and systems. (2) Material characteristics: to help students to gain knowledge about material characteristics, including structural strengths and weaknesses, as well as material life cycle analysis implications. (3) Material connections: to help learners to comprehend how to design and embody material connections and details.

Ayer et al. (2015) explored the pedagogical benefits and challenges associated with teaching a BIM project execution planning (PxP) course, which taught students about both technical BIM computer skills as well as 
high-level BIM PxP skills. In addition, it was the first indepth course that students took in the CM program at Arizona State University. Its unique features lie in its incorporation of a detailed, hands-on project that required students to demonstrate their technical skills. Another experimental BIM course, by Shanbari et al. (2015) from University of Florida, USA, explained how technology can also be used as an integral part of construction progress documentation in new AECO projects, and to impart students with knowledge about modern technologies in the AECO industry. Laser-scanning technology was introduced in a graduate BIM class by giving students a thorough demonstration on how the equipment functions, and by providing students with an opportunity to scan campus buildings to collect the point-cloud data for their respective projects. Thereby, the confidence level of students in laser-scanning technology and related processes was increased, giving them a competitive advantage in the job market.

This process of BIM education in AECO-department core courses with new concepts and directions adopted to educate students on BIM will jointly benefit academia, students, and industry.

\section{In AECO departments}

AECO departments refers to design studios and departments in the fields of $\mathrm{CM}, \mathrm{CE}$, industrial technology, construction science, BRE, and other related disciplines. Core courses within these departments involve architecture, structure, sustainable design and construction, MEP coordination, cost estimation, scheduling, contracts, materials and methods, etc. BIM courses have been experimented with by BIM educationalists from the USA, the UK, Belgium, Latvia, China, Taiwan, Indonesia, Thailand, and Malaysia in the context of AECO-related core courses. Efforts were also made to combine AECO disciplines together in order to offer students with actual industry scenarios, allowing them to collaborate, communicate, and coordinate to successfully complete the designed courses.

\section{- Architectural Engineering}

Before the industrial revolution, the architect was a master of all practices involved in the building process. With modern trends and industrialization, there has been a paradigm shift from this whole to a multiplicity of specializations in the field of architecture: this shift has altered the teaching and training processes for architecture students. Since BIM is an instrumental application of virtual reality (VR), and stands out as a technological approach to enable productive teaching and constructive learning, the integration of BIM and architectural curricula is promising for architectural education.
Architectural divisions associated with educationalists and researchers from the USA, Belgium, the UK, Indonesia, and Thailand tested architectural courses by undertaking three major steps: incorporating BIM technology as a platform, introducing training for BIM products and related processes, and by sharing their experiences, problems encountered, and misconceptions about BIM curriculum with the architecture department. Holland et al. (2010) from Pennsylvania State University, USA integrated architectural design courses using BIM as the technology platform, with their first course being integrated design studio and the second course being a two-semester capstone design course series. In these courses, most of the students felt that a BIM collaborative studio was a very effective studio learning experience. In addition, students gained valuable lessons in team and interdisciplinary work in an attempt to create a "more real-world" design process. All students agreed that $3 \mathrm{D}$ visualization and clash detection allowed for a better understanding and coordination of their design projects. Another team of architectural department educationalists from Belgium-i.e. Boeykens et al. (2013) from KU Leuven-introduced a BIM course both as a product and a process, and they found this approach to be productive. All project participants were convinced that BIM training was a valuable exercise that delivered a massive amount of knowledge to both students and educators. Salman (2014) from Robert Gordon University gave an overview of how to prepare architecture students to cope with the UK's 2016 BIM mandate. His survey results from the architectural students indicated that for BIM education, teamwork with assigned responsibilities and collaborative learning is emerging as a very important factor for effective learning. Architectural curricula are supplemented by BIM through contextual learning and teaching projects. This study indicates that the AECO industry must push its opportunities to enhance BIM practices for graduates.

Recently, Indraprahasta and Widjanarso (2015) from Institut Teknologi Bandung, Indonesia described the integration of a BIM course into a design

curriculum by evaluating and sharing their first BIM course in an architectural school. Indraprahasta and Widjanarso also explored suitable ways in which BIM can be further extended and integrated into inter-departmental courses. Another architectural department educationalist, Nakapan (2015) from Rangsit University, Thailand, has recently presented an overview of problems encountered and typical 
misconceptions about BIM curricula, based on experience from implementation of one from 2010 to 2015 taken by their first year architecture students. Their future work will focus on how to incorporate BIM design process into advanced design studios. The above studies make it clear that there are considerable efforts being undertaken by architectural division educationalists, with many educational strategies and teaching methods to integrate and enhance BIM education within architectural learning.

- Civil Engineering

$\mathrm{CE}$ is a professional engineering discipline that deals with design, construction, and maintenance of physical and naturally built environments. Integrating BIM into $\mathrm{CE}$ will enhance this discipline's capabilities in meeting current industry requirements. BIM educationalists from USA, UK, Latvia, and Taiwan related to CE divisions have experimented with BIM courses by combining knowledge with experiences. They undertook extensive reviews and analyses of visualization methods, learning basics of BIM, using integrated BIM tools, incorporating BIM concepts, and industry-academia collaborations for training $\mathrm{CE}$ students to work in a BIM-enabled world. Salazar and Gomez-Lara, M. de L (2013) described the progressive use and applications of BIM in major qualifying projects by students at the Worcester Polytechnic Institute's (WPI) Civil and EE department. Salazar and Gomez-Lara's study reviewed how integrated BIM tools are used and how BIM concepts have been incorporated into the development of projects by introducing BIM education into the curriculum. The level of sophistication and depth shown by those students who use BIM tools is increasing, surpassing simple graphic documentation of their design in 3D to the level of more-involved interoperability of building models with engineering software for structural and energy analysis. Recently, Veide and Strozheva (2015) described visualization methods of geometrical forms in the context of teaching CE students, and provided an example of 3D modeling tasks in the learning process for 2nd year undergraduate students at Riga Technical University, Latvia. Here, students were educated about how to make use of different visualization methods such as manual drawings, BIM, and AR technology to equip them with knowledge, cognition, and understanding about sustainability. The course was concluded with the realization that the introduction of modern BIM software in the education process allows $\mathrm{CE}$ students to be competitive and flexible in a rapidly changing IT environment. Another team of educationalists-Adamu and Thorpe (2015) from Loughborough University, UK-have recently discussed how growing industry demand and the UK Government's 2016 BIM mandate and its related deadline have provided a clear impetus for enhanced BIM teaching in UK higher education institutions, and reported on their approaches taken for preparing CE students for a BIM-enabled world. Current trends towards incorporating BIM into CE curricula from BIM educationalists illuminate the different tools and practices that can enhance $\mathrm{CE}$ education. More recently, a BIM education and research team at National Taiwan University, Taiwan has presented unique BIM course development features: Hsieh et al. (2015) provided an overview of a basic BIM course "Technology and Application of BIM", including the course description, teaching resources adopted, class activities, teaching methodologies, and evaluation using a lecture-lab blend with a flipped-classroom technique. Here, the course equipped CE students with a "BIM basic toolbox" containing BIM foundation skillsets: i.e. knowledge of BIM concepts and related processes, real case study-based BIM modeling, a BIM tools API, research skills, and industry collaboration. Almost all students' team projects concluded by stating that they understood the ideas behind BIM modelling and its concepts. Finally, the team shows promise towards delivering massive open online courses, i.e. BIM courses on Coursera platform.

- Construction Engineering and Management The construction industry provides graduates with several types of job positions, such as project engineer, document controller, manager, executive, coordinator, planning engineer, quantity surveyor, and estimator. The integration of BIM into CM curricula for educating students so that they suit construction industry jobs is essential. This process of integrating BIM within a CEM department's curriculum can furnish students with essential BIM concepts, technology, and process-related knowledge, and accommodate them within the current AECO industry. CEM educationalists from the USA, the UK, and Malaysia have taken efforts to conduct BIM courses for built environment, QS, and C\&FM departments. These BIM courses were tested by adopting process-oriented teaching and learning approaches, real case studies, AECO industry involvement, and constant tracking of learning outcomes.

BIM educationalists and researchers from the USA, Clevenger et al. (2010) presented efforts towards 
developing exploratory teaching modules and preliminary research findings at Colorado State University's CM department to promote BIMenabled learning. For instance, they used an editable and analyzable 3D BIM model as an exploration and visualization method to support the teaching of the fundamentals of a pin connection. Peterson et al. (2011) from Stanford University in the USA and Twente University from the Netherlands have showed how the introduction of BIM allows educators to design a class project that helps students to learn to apply different project management methods to real-world project management problems. Mahbub (2015) from Universiti Teknologi MARA examined the need for BIM inclusion within their curriculum for QS students in Malaysia. Leite (2015) from University of Texas at Austin, USA provided experiences on a BIM course they developed and described lessons learnt through teaching it over six semesters. This course was exceptionally organized with novel educational modules and industry involvement with innovative teaching approaches and process-oriented evaluation. Instructional approaches in the courses included lectures, hands-on lab-based software tutorials, team-based learning (lab-based assignments), and individual learning (reading assignments).

Another active educationalist-Korman (2015) from California Polytechnic State University, USA-has introduced CM students to sustainability concepts by developing and implementing a variety of projectbased service-learning projects. This course was designed for enhancing student-faculty contact by allowing the students and faculty to work together in a fashion different from the traditional lecturerlistener relationship. In addition, this BIM course was uniquely developed and implemented with a variety of project-based service learning types aimed at integrating sustainability into an existing curriculum. These include the REDUCE, BIM-E2, and RECA projects. In conclusion, Korman reported that service learning enhances a student's education in the areas of work ethic, critical thinking, problem solving, social issues, and reasoning. Meanwhile, Liu et al. (2015) from University of Texas at San Antonio, USA presented an introduction of the coordination process of a real-life building construction project for a BIM course. Likewise, Miller and Farnsworth (2015) from the C\&FM division of Brigham Young University, USA provided a detailed example of an introductory course integrating BIM for C\&FM students. This course was distinctive in its own way by permitting students to get hands-on experiences in areas of both C\&FM industries and by providing students with access to foundational BIM knowledge, BIM itself, scheduling and estimating. Most recently, Wu et al. (2016) from China University of Technology, Taiwan have proposed a blended learning environment that can provide students the opportunity of "learning by doing" through practice with online construction projects using web-based BIM \& cost estimating systems. Furthermore, they used TAM3 (Technology Acceptance Model 3) theory to compare acceptance between expert and novice students on this blended learning model.

From the above studies, we realize that globally, CM department educationalists are optimistic towards BIM education in TES and towards equipping students so they are prepared for current construction industry requisites.

- Multidisciplinary

Interdisciplinary learning by integrating the methodologies and fundamentals used to study common corporate problems across many AECO departments is vital to solving today's complex engineering problems. Moreover, AECO departmental course syllabi need to be enriched by engaging actual members of the AECO industry to support BIM, collaborative thinking, R\&D, and teaching and consultancy opportunities. Thus, AECO educationalists' engagement in multidisciplinary education has recently strengthened.

For instance, Solnosky et al. (2013, 2015) from Department of Architectural Engineering, Pennsylvania State University, USA conducted a series of studies presenting the development, implementation, and results of their multidisciplinary pilot program. This pilot program encompassed structural, mechanical, electrical, and construction engineering disciplines, and focused on present AEC industry needs. Their results indicated that the combination of BIM and integrated multidisciplinary collaboration have satisfied the expectations by industry reviewers (Solnosky et al. 2013). They also presented a comparison of offerings constituent courses over four years and summarized lessons learned and course management techniques developed (Solnosky et al. 2015). Three distinct methods were utilized and discussed: proposing alternative designs for existing buildings, completing design for buildings in development, and completing design for AEI National Competition. In conclusion, they emphasized a fine balance of both IPD and BIM are necessary for the best outcomes. 
Furthermore, Cribbs et al. (2015) reported on instructors' views of a cross-disciplinary approach to BIM education as a value-based approach to enhance both $\mathrm{CM}$ and architecture programs. Here, an attempt was made by educationalists from ASU to combine $\mathrm{CM}$ and architectural design students to collaboratively work on a semester course project that included design building, BIM-integrated, and real-world scenarios. They accomplished the course with the understanding that, through the use of process mapping and planning at the onset of the course, each student would understand the implications of BIM processes and the decisions that must be made to properly implement BIM on a project. More recently, Palomera-arias and Liu (2015) from University of Texas at San Antonio, USA focused on the process of developing laboratory exercises for an MEP systems course, reporting on the specific topics covered and the organization of the course during its first implementation along with drawbacks and key benefits of using BIM as part of the teaching process.

Meanwhile, Angel (2015) at University of New Mexico, USA enhanced interdisciplinary courses by integrating advanced 3D scanning in multiple phases and having more industry-academia collaboration for teaching-learning processes. Batie (2015) described an introductory BIM course to place AECO students in the role of a designer/builder by being responsible for the design and development of a small commercial building project. Moreover, the course evaluation was based on how students addressed the building design and design development, as well as their modeling abilities and inventiveness. With these newly developed BIM courses at the CM Department at East Carolina University, USA, students enhanced their estimating, scheduling, and project management abilities. These educationalists' focus in expanding the BIM course was specifically students who are interested in BIM management positions.

Aside from these experimental efforts on multidisciplinary BIM courses made by BIM educationalists and researchers in the USA, Kovačić et al. (2015) from the Institute for Interdisciplinary Building Process Management of Vienna University of Technology, Austria also reported on an interdisciplinary BIM design course. Through observations gained from their focus group study on multidisciplinary student teams, they concluded several recommendations for future interdisciplinary BIM courses: (a) impose a firm time schedule, (b) enforce verified software combinations, (c) set clear rules and responsibilities, and (d) design same input (course credits) for same course output among multidisciplinary students.

As we have reviewed, many BIM educationalists and researchers have recently experimented with courses for academic BIM education in several AECO departments by adopting a variety of methods/concepts. Almost half of the publications we collected fit into this category (33 out of 70). Many new teaching methods and concepts (e.g., open resources, professor-student collaboration, project-based learning, industry-academia alliances, career-oriented education, and sustainability) have been introduced and tested in AECO department courses to deliver BIM education. These efforts and experiences from global BIM educationalists and researchers are a rich knowledge base that other BIM educators and researchers from other places in the world can utilize. Moreover, these BIM experimentation experiences in AECO department courses can be used to develop BIM educational curricula in the future in order to advance academic BIM education further.

\section{Developing strategies to overcome BIM educational issues}

Strategy is a plan of action designed to achieve a goal/ solution to a problem. We are in need of strategies to overcome the difficulties faced by academics while experimenting with and integrating BIM into AECO departments. Globally, active BIM educationalists and researchers are integrating BIM into academia, and during this process, they have experienced some difficulties related to policy, technology, and processes. Policy issues include barriers such as lack of motivation, non-uniform global accreditation, professional accreditation issues, BIM curriculum issues, and diverse BIM modeling skill requirements. Technology issues include problems such as BIM tool selection, BIM software licenses, BIM technical affairs, as well as the need for BIM IT lab facilities, object libraries, and coordination tools. Process issues include problems such as weak ties between industry and academia, the need for trans- disciplinary, interlevel, and multinational collaboration, and incomplete BIM curricula. BIM activists and educationalists have put effort into resolving these BIM educational issues.

The first serious discussions and analyses of BIM educational issues were begun in early 2012 by Brazilian educationalists, and were taken up by Australian researchers in mid-2013 with regard to BIM curricula and more recently in Malaysia with regard to BIM-TES. Barison and Santos (2012b) addressed the main obstacles encountered with BIM teaching and introduced new strategies to overcome them. In this study, obstacles were grouped into three categories: academic environment, BIM concepts, and BIM tools. Academic 
environment includes time, motivation, resources, accreditation, and curriculum. BIM concepts includes individualized instruction, traditional teaching, little teamwork, and lack of collaboration. BIM tools include creativity, learning, teaching, and knowledge. To overcome these obstacles, new strategies with three different BIM course levels such as introductory, intermediary, and advanced levels were presented. The introductory level consisted of a digital graphic representation course. The intermediary level consisted of an integrated design studio and building technology courses. The advanced level involved an interdisciplinary design studio and CM course. Another team of educationalists, i.e. Panuwatwanich et al. (2013) from Australia, explored and discussed issues faced in the context of integrating BIM into curricula. This study found six major barriers to integrating BIM into higher education: (1) disagreement over BIM concepts, (2) traditional program structures, (3) need for strong fundamental knowledge, (4) need for industry involvement, (5) resistance to change, and (6) professional accreditation issues. Moreover, these challenges can happen to all disciplines within AECO.

Recently, Hedayati et al. (2015) studied obstacles to implementing BIM in TES and made further recommendations. They identified major barriers and asked both students and lecturers to rank them. Students ranked the top three barriers as: (1) lecturers' unwillingness to change traditional working practices, (2) high cost of and extensive training on software, and (3) older lecturers being uncomfortable with newer technologies and practices. Lecturers ranked them as: (1) unsuitability of some university projects to BIM adoption, (2) the institution's unwillingness to invest in new syllabi, and (3) legal barriers to starting a new BIM course. In addition, another survey was conducted among lecturers to rank the strategies to overcome these barriers. The top three recommended strategies were: (1) training lecturers on new software technology, (2) realizing value from facilitating the construction process, and (3) purchasing software and technology.

To our understanding, players in the BIM field are working towards resolving these technology-, process-, and policy-related issues, thereby helping BIM educators to easily and seamlessly integrate BIM into TESs.

\section{Conclusion}

The objective of this review was to provide an overview of the efforts of educationalists and researchers around the globe to deliver academic BIM education in advanced engineering courses with visualization components. Our study investigated the latest publications on academic BIM education. Seventy publications ranging from 2010 to date from 24 countries were collected. The process of literature review and textual analysis resulted in six conceptual categories into which BIM educationalists and researchers' efforts were grouped: (a) identifying needs for BIM in TEIs, (b) identifying essential BIM skillsets for BIM education, (c) developing BIM educational frameworks, (d) developing BIM curricula, (e) experimenting with BIM courses, and (f) developing strategies to overcome BIM educational issues. These categorization and review of the collected publications can serve as a knowledge base for other BIM educators to: (a) realize major issues involved in BIM education, (b) develop strategies to incorporate BIM into TESs, and (c) develop BIM tertiary education frameworks and curricula that can take global BIM education in TESs to the next level.

Moreover, through analyzing global BIM education research trends, this study provides future research suggestions for academic BIM education across the globe. More detailed research needs to be conducted on delivering academic BIM education in different national contexts, AECO disciplines, and TES levels. More research on BIM educational frameworks and curriculum development needs to be done as well. Furthermore, our review and analysis of these tertiary BIM education publications highlight the relationship between academic BIM education and visualization: high visualization competencies in using 3D to $\mathrm{nD}$ BIM have been recognized as one of the essential skillsets cultivated by academic BIM education across different AECO departments around the world. In fact, these visualization skills are being taught in different AECO schools across the globe currently. With the rapid diffusion of BIM in AECO education across the globe, advanced engineering communications through medium of visualization can be achieved and realized not only in academia but also in industry in the near future.

This study also provides a foundation for ongoing study into major issues involved in delivering academic BIM education. Four questions have arisen that will be answered going forward. First, is BIM just an addition to the original curriculum? Second, what about BIM should be learnt, and at which level of the educational process? Third, how do BIM education approaches differ around the globe? Fourth, what are the education- and researchrelated issues faced by BIM education? Efforts are underway to develop strategies to address major obstacles faced by BIM teaching.

\section{Authors' contributions}

ACB carried out literature review, conceptual categorization and drafted the manuscript. YTC developed diagram, interactive map and co-drafted the manuscript. SHH guided the research and revised the manuscript.

\section{Competing interests}

The authors declare that they have no competing interests.

Received: 13 February 2016 Accepted: 7 June 2016

Published online: 16 June 2016 


\section{References}

Adamu ZA \& Thorpe, T (2015). How should we teach BIM ? A case study from the UK. In proceedings of 9th BIM Academic Symposium and Job Task Analysis Review, Washington, DC, 7-8th April (pp. 80-87).

Agboola, OP, \& Elinwa, UK (2013). Accreditation of Engineering and Architectural Education in Nigeria: The Way forward. Procedia - Social and Behavioral Sciences, 83, 836-840.

AIA-CA (2012). BIM in Practice - BIM Education. Position paper by the Australian Institute of Architects and Consult Australia.

Ali, KN, Mustaffa, NE, Keat, QJ, \& Enegbuma, WI (2015). BIM Educational Framework for Quantity surveying students: The Malaysian perspective. Proceedings of 9th BIM Academic Symposium and Job Task Analysis Review, Washington, DC, 7-8th April (pp. 120-128).

Angel, GM (2015). BIM Course development and integration in a multi-discipline Civil Engineering Department. Proceedings of 9th BIM Academic Symposium and Job Task Analysis Review, Washington, DC, 7-8th April (pp. 42-49).

Ayer, SK, Cribbs, J, Hailer, JD, \& Chasey, AD (2015). Best Practices and lessons learned in BIM Project Execution Planning in Construction Education. Proceedings of 9th BIM Academic Symposium and Job Task Analysis Review, Washington, DC, 7-8th April (pp. 167-174).

Barison, MB, \& Santos, ET (2010). Review and analysis of current strategies for planning a BIM Curriculum. Proceedings of CIB W78 2010 27th International Conference.

Barison, MB, \& Santos, ET (2010b). An overview of BIM specialists. Proceedings of the International Conference on Computing in Civil and Building Engineering (icccbe2010). Nottingham, UK: Nottingham university Press.

Barison, MB, \& Santos, ET (2010c). BIM teaching strategies: an overview of the current approaches. Proceedings of the International Conference on Computing in Civil and Building Engineering (icccbe 2010). Nottingham, UK: Nottingham University press.

Barison, MB, \& Santos, ET (2011). The competencies of BIM specialists: a comparative analysis of the literature review and job ad descriptions. Proceedings of International Workshop on Computing in Civil Engineering. Reston, VA: ASCE.

Barison, MB, \& Santos, ET (2012a). A Theoretical Model for the Introduction of BIM into the Curriculum. Proceedings of 7th International Conference on Innovation in Architecture, Engineering and Construction (AEC 2012), 15-17th August. São Paulo, Brazil: Brazilian British Centre.

Barison, MB, \& Santos, ET (2012b). BIM Teaching: Current International Trends. Ensino de BIM: tendências atuais no cenário internacional, 6(2), 67-80.

Barison, MB, \& Santos, ET (2013). Educational Activities for the Teaching-Learning of BIM. Proceedings of I BIM International Conference (BIC 2013), 20-21st June, Porto, Portugal.

Barison MB, \& Santos ET. (2014). A Tool for Assisting Teachers in Planning BIM Courses. Computing in Civil and Building Engineering. ASCE (pp. 2159-2166).

Batie, DL (2015). Introductory BIM Class - Design/Builder Project. Proceedings of 9th BIM Academic Symposium and Job Task Analysis Review, Washington, DC, 7-8th April (pp. 50-57).

Becerik-Gerber, B, Gerber, DJ, \& Ku, K (2011). The pace of technological innovation in architecture, engineering, and construction education: Integrating recent trends into the curricula. Electronic Journal of Information Technology in Construction, 16, 411-432.

Becker, TC, Jaselskis, EJ, \& Mcdermott, CP (2011). Implications of Construction Industry Trends on the Educational Requirements for Future Construction Professionals. Proceedings of 47th ASC Annual International Conference. Omaha, Nebraska, United States, 6-9th April.

Boeykens, S, Somer, P De, Klein, R, \& Saey, R (2013). Experiencing BIM Collaboration in Education. Proceedings of the 31st International Conference on Education and research in Computer Aided Architectural Design in Europe (eCAADe 2013: Computation and Performance), Delft, Netherlands, 18-20th September (pp. 505-513).

Cheng, JC, \& Lu, Q (2015). A review of the efforts and roles of the public sector for BIM adoption worldwide. ITcon Vol. 20, (pp. 442-478)

Clevenger, CM, Ozbek, M, Glick, S \& Porter, D (2010). Integrating BIM into Construction Management Education. EcoBuild Proceedings of the BIMRelated Academic Workshop.

Computer Integrated Construction Research Group (2011). BIM Project Execution Planning Guide V2.1. The Pennsylvania State Unversity, UNiversity Park, PA, USA. http://bim.psu.edu/Project/resources/default.aspx.

Cribbs, J, Hailer, JD, Horton, P, \& Chasey, A (2015). Enhanced Collaboration between Construction Management and Architecture students utilizing a BIM Environment. Proceedings of 9th BIM Academic Symposium and Job Task Analysis Review, Washington, DC, 7-8th April (pp. 159-166).
Dederichs, AS, Karlshøj, J, \& Hertz, K (2010). Multidisciplinary Teaching: Engineering Course in Advanced Building Design. Journal of Professional Issues in Engineering Education and Practice, 137(1), 12-19.

Demirdoven, J (2015). An Interdeciplinary Approach to integrate BIM in the Construction Management and Engineering Curriculum. Proceedings of 9th BIM Academic Symposium and Job Task Analysis Review, Washington, DC, 7-8th April (pp. 112-119).

Dossick, CS, Anderson, A, Homayouni, H, \& Monson, C (2015). Exploring Flip for BIM: tutorials at home, Exercises in Lab. Proceedings of 9th BIM Academic Symposium and Job Task Analysis Review, Washington, DC, 7-8th April (pp. 64-71).

Elinwa, UK, \& Agboola, OP (2013). Beyond BIM - A Classroom Approach To Virtual Design Education. Procedia - Social and Behavioral Sciences, 83(x), 393-397.

Gardner, JCH, Hosseini, MR, \& Rameezdeen, R (2014). Building Information Modelling (BIM) Education in South Australia : Industry Needs (pp. 293-302).

Gegana, G \& Widjarnarso, TH (2015). BIM Course development and its future Integration at University of Indonesia and Institute of Technology Bandung, Indonesia. In proceedings of 9th BIM Academic Symposium and Job Task Analysis Review, Washington, DC, 7-8th April (pp. 10-17).

Graham, TE, Shofoluwe, MA, \& Pyle, RB (2015). Industry-Academic BIM Alliance: a Pragmatic Approach to Enhance Students' BIM Knowledge. Proceedings of 9th BIM Academic Symposium and Job Task Analysis Review, Washington, DC, 7-8th April (pp. 72-79).

Hedayati, A, Mohandes, SR, \& Preece, C (2015). Studying the Obstacles to Implementing BIM in Educational System and making some Recommendations. Journal of Basic Applied Science Research, 5(3), 29-35.

Heintz, E. (2010). Transforming design education. Proceedings of 3rd International Conference on Internet Technologies and Applications, iTAP, Wuhan City, China (pp. 1-4).

Henderson, L, \& Jordan, N (2015). Two year Graduate Transdisciplinary Building Lifecycle core Curriculum. Proceedings of 9th BIM Academic Symposium and Job Task Analysis Review, Washington, DC, 7-8th April (pp. 151-158).

Hoang, H, \& Bedrick, J (2015). BIM Education in Asean: the demand for BIM practitioners. Proceedings of 9th BIM Academic Symposium and Job Task Analysis Review, Washington, DC, 7-8th April (pp. 191-198).

Holland, R, Messner, J, Parfitt, K, Poerschke, U, Pihlak, M, \& Solnosky, R (2010). Integrated Design Courses Using BIM as the Technology Platform. In Integrated design courses using BIM as the technology platform.

Hsieh, S, Amarnath, CB, \& Tsai, Y. (2015). On teaching bim technology courses in civil engineering. Proceedings of International Conference on Innovative Production and Construction, IPC 2015, 28-31st July, Perth, Western Australia, Australia.

Indraprahasta, A, \& Widjanarso, TH (2015). Integration of BIM course into Design curriculum case study: study program of Architecture, institut Teknologi Bandung. Proceedings of 9th BIM Academic Symposium and Job Task Analysis Review, Washington, DC, 7-8th April (pp. 137-144).

Jeon, JW, \& Eom, SJ (2011). Case Study: Development of Bim U-Education System With Open Bim Library. Proceedings of 28th ISARC 2011, Seoul, Korea (pp. 570-571).

Joannides, MM, Olbina, S, \& Issa, RRA (2012). Implementation of Building Information Modeling into Accredited Programs in Architecture and Construction Education. International Journal of Construction Education and Research, 8(2), 83-100. http://doi.org/10.1080/15578771.2011.632809.

Korman, TM (2015). Integrating sustainability concepts into construction engineering education through service learning projects. Proceedings of 7 th International Conference on Engineering Education for sustainable Development, Vancouver, Canada, 9-12th June (pp. 1-7).

Kovačić, I, Filzmoser, M, Kiesel, K, Oberwinter, L, \& Mahdavi, A (2015). BIM teaching as support to integrated design practice. Journal of the Croatian Association of Civil Engineers, 67(6), 537-546. http://doi.org/10.14256/JCE.1163.2014.

Lee, N, \& Dossick, CS (2012). Leveraging Building Information Modeling technology in Construction Engineering and Management education. In Proceedings of 119th ASEE Annual Conference, San Antonio, 10-13th June. San Antonio: ASEE.

Lee, N, Dossick, CS, \& Foley, SP (2013). Guideline for Building Information Modeling in Construction Engineering and Management Education. Journal of Professional Issues in Engineering Education and Practice, 139(4), 266-274.

Leite, F (2015). An example Project-Based Course on Building Information Modeling for Construction. Proceedings of 9th BIM Academic Symposium and Job Task Analysis Review, Washington, DC, 7-8th April (pp. 58-63). 
Liu, R, Gajbhiye, A, \& Paromera-arias, R (2015). Using real life examples of Building Construction for student projects to improve their understanding and concept of BIM Implementation. Proceedings of 9th BIM Academic Symposium and Job Task Analysis Review, Washington, DC, 7-8th April (pp. 96-103).

Liu, R, \& Hatipkarasulu, Y. (2014). Introducing Building Information Modeling Course into a Newly Developed Construction Program with Various Student Backgrounds. In Proceedings of 121st ASEE Annual Conference and Exposition. Indianapolis, Indiana: ASEE.

Macdonald, JA (2012). A Framework for Collaborative BIM Education across the AEC Disciplines. Proceedings of AUBEA 2012, Sydney, Australia, 4-6th July, (pp. 223-230).

Mahbub, R (2015). Effective Teaching of Technology: Building Information Modelling (BIM) Module for Built Environment Students. In Proceedings of the 14th International Conference on Education and Educational Technology (EDU'15) (pp. 23-25).

Mcdonald, M, \& Donohoe, S (2013). How are the Educational Institutes of Ireland Embracing the Paradigm Shift towards BIM?. Proceedings of CITA BIM Gathering, Dublin, Ireland, 14-15th November.

Miller, K., \& Farnsworth, C.B. (2015). Introductory Course to Construction and Facilities Management at Brigham Young University. Proceedings of 9th BIM Academic Symposium and Job Task Analysis Review, Washington, DC, 7-8th April (pp. 145-150)

Nakapan, W (2015). Challenge of teaching BIM in the first year of University: Problems encountered and typical misconceptions to avoid when integrating BIM into an Architectural design curriculum. Proceedings of the 20th International Conference of the Association for Computer-Aided Architectural Design Research in Asia, CAADRIA 2015, Hong Kong.

Palomera-arias, R, \& Liu, R (2015). Developing BIM laboratory exercises for a MEP systems course in a construction science and management program. Proceedings of 9th BIM Academic Symposium and Job Task Analysis Review, Washington, DC, 7-8th April (pp. 88-95).

Panuwatwanich, K, Wong, ML, Doh, JH, Stewart, RA, \& McCarthy, TJ (2013). Integrating BIM into Engineering education: an exploratory study of industry perceptions using social network data. Proceedings of the 24th Annual Conference of the Australian Association for Engineering Education.

Peterson, F, Hartmann, T, Fruchter, R, \& Fischer, M (2011). Teaching construction project management with BIM support: Experience and lessons learned. Automation in Construction, 20(2), 115-125. doi:10.1016/j.autcon.2010.09.009.

Pikas, E, Sacks, R, \& Hazzan, O (2013). Building information modeling education for construction engineering and management. II: Procedures and implementation case study. Journal of Construction Engineering and Management, 139(11), 1-12.

Rooney, K (2015). BIM Education - Global Summary 2015 Update Report. Sydney, Australia: NATSPEC Construction Information.

Sacks, R, \& Pikas, E (2013). Building Information Modeling Education for Construction Engineering and Management. I: Industry Requirements, State of the Art, and Gap Analysis. Journal of Construction Engineering and Management, 139(11), 04013016. http://doi.org/10.1061/(ASCE)CO.1943-7862.0000759.

Salazar, GF \& Gomez-Lara, M de L (2013). Use of Building Information Modeling in Student Projects at WPI. Proceedings of the Building SMART Alliance BIMForum Conference.

Salazar, GF, Romero, SA, \& Gomez-Lara, M de L (2015). Building a BIM-based Platform to support delivery of Construction methods and Virtual Construction courses at different Universities. Proceedings of 9th BIM Academic Symposium and Job Task Analysis Review, Washington, DC, 7-8th April (pp. 104-111).

Salman, H (2014). Preparing Arcihtectural technology students for BIM 2016 mandate. Proceedings of the 4th international Congress of Architectural Technology, 22nd March, Sheffield: ICAT (pp. 142-158).

Sampaio, AZ (2014). The BIM Concept: The Role of the Engineering School, Using Technology Tools to Innovate Assessment, Reporting, and Teaching Practices in Engineering Education, 190

Shanbari, H, Blinn, N, \& Issa, RR (2015). Intoducing Laser Scanning Technology in a Graduate BIM Class. Proceedings of 9th BIM Academic Symposium and Job Task Analysis Review, Washington, DC, 7-8th April (pp. 183-190).

Solnosky, R, Parfitt, MK, \& Holland, RJ (2013). IPD and BIM-Focused Capstone Course Based on AEC Industry Needs and Involvement. Journal of Professional Issues in Engineering Education and Practice, 140(4), A4013001. doi:10.1061/(ASCE)El.1943-5541.0000157.
Solnosky, R, Parfitt, MK, \& Holland, R (2015). Delivery methods for a multidisciplinary architectural engineering capstone design course. Architectural Engineering and Design Management, 11(ahead-of-print), 1-20. http://doi.org/10.1080/17452007.2014.925418

Stone, TA, \& King, M (2015). Design disassembled: Understanding Building systems through BIM. Proceedings of 9th BIM Academic Symposium and Job Task Analysis Review, Washington, DC, 7-8th April (pp. 175-182).

Succar, B (2015). BIM ThinkSpace episode 24: Understanding Model Uses. Retrieved from BIM Think Space website: http://www.bimthinkspace.com/. Accessed 10 Sept 2015

Succar, B, \& Sher, W (2013). A Competency Knowledge-base for BIM Learning. Proceedings of 38th Australasian Universities Building Education Association Conference, AUBEA 2013, Auckland, NZ, 20-22nd November.

Succar, B, \& Sher, W (2014). A competency knowledge-base for BIM learning. Australasian Journal of Construction Economics and Building-Conference Series, 2(2), 1-10.

Succar, B, Sher, W, \& Williams, A (2013). An integrated approach to BIM competency assessment, acquisition and application. Automation in Construction, 35, 174-189.

Suwal, S, Jäväjä, P, \& Salin, J (2014). BIM Education: Implementing and Reviewing "OpeBIM" - BIM for Teachers. In The Sixth International Conference on Computing in Civil and Building Engineering (pp. 2151-2158). http://doi.org/10.1061/9780784413616.053

Underwood, J, \& Ayoade, O. (2015). Current Position and Associated Challenges of BIM education in UK Higher Education

Veide, Z, \& Strozheva, V (2015). The Visualizations Methods of Geometrical Forms in teaching of Civil Engineering Students. Proceedings of the 10th International Scientific and Practical Conference, rezeke, Lativa (pp. 312-316).

Wong, KA, Wong, KF, \& Nadeem, A (2011). Building information modelling for tertiary construction education in Hong Kong. Journal of Information Technology in Construction, 16, 467-476.

Wu, W, \& Issa, RRA (2013). BIM Education for new careers options: an initial investigation. In BIM Academic Workshop, Washington, DC. U.S., 11 th January.

Wu, W, \& Luo, Y (2015). Project-Based Learning for Enhanced BIM Implementation in the Sustainability Domain. Proceedings of 9th BIM Academic Symposium and Job Task Analysis Review, Washington, DC, 7-8th April (pp. 2-9).

Wu, Y, Wen, M, Chen, C, \& Hsu, I (2016). An Integrated BIM And Cost Estimating Blended Learning Model - Acceptance Differences Between Experts And Novice. Eurasia Journal of Mathematics, Science \& Technology Education, 12(5), 1347-1363. http://doi.org/10.12973/eurasia.2016.1517a.

\section{Submit your manuscript to a SpringerOpen ${ }^{\circ}$ journal and benefit from:}

- Convenient online submission

- Rigorous peer review

- Immediate publication on acceptance

- Open access: articles freely available online

- High visibility within the field

- Retaining the copyright to your article

Submit your next manuscript at springeropen.com 